Research Article

\title{
Effect of $\mathrm{Eu}^{3+}$ Concentration on the $\mathrm{BaAl}_{2} \mathrm{O}_{4} / \mathrm{CaAl}_{4} \mathrm{O}_{7}: x \% \mathrm{Eu}^{3+}$ $(0 \leq x \leq 5.5)$ Mixed-Phase Nanophosphors Synthesized Using Citrate Sol-Gel Method
}

\author{
Bamba Mahman (iD) and Mpho Enoch Sithole \\ Department of Physics, Sefako Makgatho Health Sciences University, P. O. Box 94, Medunsa 0204, South Africa \\ Correspondence should be addressed to Bamba Mahman; mahmanbamba@gmail.com
}

Received 28 May 2021; Accepted 6 September 2021; Published 18 September 2021

Academic Editor: Guang xing Liang

Copyright (c) 2021 Bamba Mahman and Mpho Enoch Sithole. This is an open access article distributed under the Creative Commons Attribution License, which permits unrestricted use, distribution, and reproduction in any medium, provided the original work is properly cited.

\begin{abstract}
A series of undoped mixed-phase $\mathrm{BaAl}_{2} \mathrm{O}_{4} / \mathrm{CaAl}_{4} \mathrm{O}_{7}$ (hereafter called $\mathrm{BC}$ ) and doped $\mathrm{BC}: x \% \mathrm{Eu}^{3+}(0<x \leq 5.5)$ nanophosphors were successfully prepared by the citrate sol-gel technique. Their structure, morphology, and optical properties were studied in detail by X-ray diffraction (XRD), scanning electron microscopy (SEM), transmission electron microscopy (TEM), and photoluminescence (PL) spectroscopy. XRD and SEM showed that all the $\mathrm{BC}: x \% \mathrm{Eu}^{3+}$ samples consisted of the crystalline structure of the mixed phases of both the $\mathrm{BaAl}_{2} \mathrm{O}_{4}$ and $\mathrm{CaAl}_{4} \mathrm{O}_{7}$ materials. The structure resembles more that of the $\mathrm{BaAl}_{2} \mathrm{O}_{4}$ than the $\mathrm{CaAl}_{4} \mathrm{O}_{7}$ phase. The TEM results suggest that the crystallite sizes are in the nanometer scale with rod-like particles. PL results showed multiple emission peaks located at 436, 590,616, 656, and $703 \mathrm{~nm}$, which were assigned to the intrinsic defects within the BC matrix, ${ }^{5} \mathrm{D}_{0} \longrightarrow{ }^{7} \mathrm{~F}_{1},{ }^{5} \mathrm{D} 0 \longrightarrow{ }^{7} \mathrm{~F}_{2},{ }^{5} \mathrm{D}_{0} \longrightarrow{ }^{7} \mathrm{~F}_{3}$, and ${ }^{5} \mathrm{D}_{0} \longrightarrow{ }^{7} \mathrm{~F}_{4}$ transitions of $\mathrm{Eu}^{3+}$, respectively. The decay curves evidently showed that the nanophosphors have persistent luminescence. The Commission Internationale de l'Eclairage (CIE) analysis revealed that doping has tuned the emission colour from blue to orange-red. The results indicate that the $\mathrm{Eu}^{3+}$-doped samples can potentially be used in the orange/red-emitting phosphors.
\end{abstract}

\section{Introduction}

The emission of light from a material originates from two types of mechanisms, namely, thermal and luminescence processes. In the luminescence process, the electrons of the impurity ions are excited by the external source to higher energy levels and emit light when they are falling to their ground state levels [1]. In the recent decades, a class of materials or substances which emit characteristic luminescence, called phosphors, and are emitting visible light under the external excitation wavelength have particularly attracted much attention as wavelength converters for lightemitting diodes (LEDs) [2, 3]. Stefani et al. [4] and Mu et al. [5] reported that $\mathrm{BaAl}_{2} \mathrm{O}_{4}: \mathrm{Eu}^{2+}$ nanophosphors have stuffed tridymite structures, which are complicated structures. Adding to that, there is a size mismatch between $\mathrm{Ba}^{2+}$ and $\mathrm{Eu}^{2+}$, which could result in other impurity phase formations at the high $\mathrm{Eu}^{2+}$ concentration. This is why $\mathrm{BaAl}_{2} \mathrm{O}_{4}: \mathrm{Eu}^{2+}$ is infrequently studied. Furthermore, it could cause the distortion of the crystal lattice and subsequently deteriorate the crystallinity of the phosphor [3]. However, $\mathrm{BaAl}_{2} \mathrm{O}_{4}$ : $\mathrm{Eu}^{2+}, \mathrm{Dy}^{3+}$ is a promising host material for long afterglow phosphorescence [6]. $\mathrm{BaAl}_{2} \mathrm{O}_{4}: \mathrm{Ce}^{3+}$ with long lasting afterglow for more than $10 \mathrm{~h}$ due to cationic defects has been reported [7]. On the other hand, fluorescence phosphors such as calcium aluminates $\left(\mathrm{CaAl}_{2} \mathrm{O}_{4}\right.$ and $\left.\mathrm{CaAl}_{4} \mathrm{O}_{7}\right)$, which are good examples of the materials exhibiting a long lasting afterglow, have found application in light-emitting devices such as plasma display panels, medical lamps, and fluorescent lamps [8]. To this end, the europium ions can be introduced into the $\mathrm{CaAl}_{2} \mathrm{O}_{4}, \mathrm{CaAl}_{4} \mathrm{O}_{7}$, or $\mathrm{BaAl}_{2} \mathrm{O}_{4}$ lattice in its trivalent $\left(\mathrm{Eu}^{3+}\right)$ or divalent $\left(\mathrm{Eu}^{2+}\right)$ state or both of them at the same time [9]. $\mathrm{Eu}^{2+} / \mathrm{Eu}^{3+}$-doped $\mathrm{CaAl}_{2} \mathrm{O}_{4}, \mathrm{CaAl}_{4} \mathrm{O}_{7}$, $\mathrm{BaAl}_{2} \mathrm{O}_{4}$, or $\mathrm{Ba}_{\mathrm{x}} \mathrm{Ca}_{1-\mathrm{x}} \mathrm{Al}_{2} \mathrm{O}_{4}$ has been prepared using different techniques such as combustion method [10-12], solid state reaction $[4,13,14]$, microwave [14], Pechini method 
[15], and sol-gel synthesis methods [7, 16]. Sol-gel synthesis has some advantages over other synthesis techniques, for example, operating under relatively low temperature, easy control of stoichiometry, and high level of product homogeneity, and it is a cheap synthesis method [15]. Furthermore, the high versatility of the sol-gel process makes it possible to obtain various compositions and to vary the nature and the concentration of the doping ion easily. The sol-gel process provides an ideal way to control the level of doping, which is a crucial point for scintillating materials [17]. In $\mathrm{BaAl}_{2} \mathrm{O}_{4}: \mathrm{Eu}^{3+}(1 \mathrm{~mol} \%)$ codoped with varying concentration of $\mathrm{Gd}^{3+}$, it was observed that $\mathrm{Eu}^{3+}$ was reduced to $\mathrm{Eu}^{2+}$. Consequently, the prepared phosphor at $600^{\circ} \mathrm{C}$ exhibited a high intense broad peak around $498 \mathrm{~nm}$ due to $\mathrm{Eu}^{2+}$ and small peaks in the red region assigned to the presence of $\mathrm{Eu}^{3+}[10]$. Similar observations concerning a peak around 496 and small peaks around $600 \mathrm{~nm}$ were reported in $\mathrm{Ba}_{4} \mathrm{Al}_{14} \mathrm{O}_{25}$ : Eu, Dy [11]. The peaks around 496 and $498 \mathrm{~nm}$ were attributed to the $4 \mathrm{f}^{6} 5 \mathrm{~d}^{1} \longrightarrow 4 \mathrm{f}^{7}$ transition of $\mathrm{Eu}^{2+}$, while the peak at $600 \mathrm{~nm}$ was ascribed to the ${ }^{5} \mathrm{D}_{0} \longrightarrow{ }^{7} \mathrm{~F}_{\mathrm{j}}(j=0-4)$ transitions of $\mathrm{Eu}^{3+}$. Moreover, the XRD results showed that codoping $\mathrm{BaAl}_{2} \mathrm{O}_{4}$ with $\mathrm{Eu}^{3+}$ and $\mathrm{Gd}^{3+}$ did not change the crystal structure. It was reported that the material composition, dimensions, morphology, and phase had a great effect on the spectrum and optical temperature behavior of rare Earth ions doped phosphors [18]. It was found that at high temperature significant fluorescence quenching occurs when the samples are pure $\mathrm{GdF}_{3}$ and pure $\mathrm{NaGdF}_{4}$, respectively. However, the fluorescence intensity of the mixed-phase $\mathrm{GdF}_{3}: 2 \% \mathrm{Er}^{3+}$ and $\mathrm{NaGdF}_{4}: 2 \% \mathrm{Er}^{3+}$ was not quenched at the high temperature more than $473 \mathrm{~K}$. This implies that the temperature sensing properties were improved in the mixed phase [19]. Moreover, Maphiri et al. [20] reported that, in $\mathrm{Ba}_{1-x} \mathrm{Zn}_{x} \mathrm{Al}_{2} \mathrm{O}_{4}: 0.1 \% \mathrm{Eu}^{3+}$, consisting of $\mathrm{BaAl}_{2} \mathrm{O}_{4}$ and $\mathrm{ZnAl}_{2} \mathrm{O}_{4}$ phases, the PL emission intensity depended on $\mathrm{Zn}$ moles. Furthermore, they have observed a phase transfer from the mixed-phase $\mathrm{Ba}_{1-x} \mathrm{Zn}_{x} \mathrm{Al}_{2} \mathrm{O}_{4}: 0.1 \%$ $\mathrm{Eu}^{3+}$ to the single-phase $\mathrm{ZnAl}_{2} \mathrm{O}_{4}: 0.1 \% \mathrm{Eu}^{3+}$ by replacing $\mathrm{Ba}^{2+}$ ions with $\mathrm{Zn}^{2+}$ ions. $\mathrm{Lv}$ et al. [21] prepared $\mathrm{LiCa}_{3} \mathrm{MgV}_{3-x} \mathrm{~W}_{x} \mathrm{O}_{12}$ (short as LMCV-W-X) combined with vanadate and tungsten oxides by sol-gel method. The photoluminescence quantum yield has significantly enhanced to $64,3 \%$. Furthermore, the luminescence characteristics of tungsten oxide made LMCV-W-X fluorescence performance change with the change of tungsten content. Suriyamurthy and Panigrahi [16] reported an enhancement of the $\mathrm{Ce}^{3+}$ emission intensity of $\mathrm{BaAl}_{2} \mathrm{O}_{4}: \mathrm{Ce}^{3+}$ more than five times when replacing $\mathrm{Ba}^{2+}$ with $\mathrm{Ca}^{2+}$ ion to form $\mathrm{Ba}_{1-x} \mathrm{Ca}_{x} \mathrm{Al}_{2} \mathrm{O}_{4}: \mathrm{Ce}^{3+}(x=0.02 \mathrm{M})$ phosphors; the reason for such an enhancement was not clear. Yerpude et al. [22] have prepared a $\mathrm{BaCa}_{2} \mathrm{Al}_{8} \mathrm{O}_{15}: \mathrm{Eu}^{2+}, \mathrm{Dy}^{3+}$ phosphor using the combustion method. They observed a broadband excitation spectrum, which peaks at $334 \mathrm{~nm}$ when monitoring the emission at $435 \mathrm{~nm}$ and that was assigned to the $4 \mathrm{f}^{5} 5 \mathrm{~d}^{1} \longrightarrow 4 \mathrm{f}^{7}$ transition of $\mathrm{Eu}^{2+}$. They also observed blue long-lasting phosphorescence (BLLP) for several minutes in the dark when the light source was removed. The BLLP was attributed to the presence of $\mathrm{Dy}^{3+}$ ions which act as hole traps. There was no emission from $\mathrm{Eu}^{3+}$ suggesting that all the $\mathrm{Eu}^{3+}$ ions in the crystal matrix had been completely reduced to $\mathrm{Eu}^{2+}[15,23]$. It is clear from the above studies that mixed phases in phosphors have more exceptional luminescence and fluorescence performance than singlephase phosphors. Based on those results and the good optical properties of $\mathrm{BaAl}_{2} \mathrm{O}_{4}$ and $\mathrm{CaAl}_{4} \mathrm{O}_{7}$, it was anticipated that having $\mathrm{BaAl}_{2} \mathrm{O}_{4}$ and $\mathrm{CaAl}_{4} \mathrm{O}_{7}$ phases in the same matrix could result in the formation of a mixed-phase $\mathrm{BC}$, with better optical properties than the pure $\mathrm{BaAl}_{2} \mathrm{O}_{4}$ and pure $\mathrm{CaAl}_{4} \mathrm{O}_{7}$ phases. To the best of our knowledge, no studies are reported yet on the $\mathrm{BC}: x \% \mathrm{Eu}^{3+}$ nanophosphors. Firstly, the purpose of this work is to develop the phosphor material composed of the mixed phases of both $\mathrm{BaAl}_{2} \mathrm{O}_{4}$ and $\mathrm{CaAl}_{4} \mathrm{O}_{7}$. The idea is to develop the phosphor material, which might have combined properties of the bulk $\mathrm{BaAl}_{2} \mathrm{O}_{4}$ and $\mathrm{CaAl}_{4} \mathrm{O}_{7}$. Secondly, this study investigates the effects of the $x \% \mathrm{Eu}^{3+}$ on the structure, morphology, and PL properties of the BC: $x \% \mathrm{Eu}^{3+}(0 \leq x \leq 5)$ nanophosphors. The main aim is to produce a phosphor material, which could be utilized in the practical application such as on light-emitting devices. The mechanisms related to the observed emissions are also described in detail.

\section{Experimental Details}

2.1. Sample Preparation. $\mathrm{BaAl}_{2} \mathrm{O}_{4}, \mathrm{CaAl}_{4} \mathrm{O}_{7}$, and $\mathrm{BC}: x \%$ $\mathrm{Eu}^{3+}(0 \leq x \leq 5.5)$ phosphors were prepared using the citrate sol-gel technique, where citric acid $\left(\mathrm{C}_{8} \mathrm{H}_{8} \mathrm{O}_{7} \cdot \mathrm{H}_{2} \mathrm{O}\right)$ was used as a chelating agent. Various metal nitrates such as aluminium nitrate nanohydrate $\left(\mathrm{Al}\left(\mathrm{NO}_{3}\right)_{3} \cdot 9 \mathrm{H}_{2} \mathrm{O}\right)$ (98\%), barium nitrate hexahydrate $\left(\mathrm{Ba}\left(\mathrm{NO}_{3}\right)_{2} \cdot 6 \mathrm{H}_{2} \mathrm{O}\right)(99 \%)$, and calcium nitrate hexahydrate $\left(\mathrm{Ca}\left(\mathrm{NO}_{3}\right)_{2} \cdot 6 \mathrm{H}_{2} \mathrm{O}\right)(99 \%)$ were used as starting reagents for the undoped phosphors materials. Specified amounts of europium (III) nitrate $\left(\mathrm{Eu}\left(\mathrm{NO}_{3}\right)_{3}\right)(99 \%)$ were used to dope BC at different $x \% \mathrm{Eu}^{3+}$ concentration in a range of $0 \leq x \leq 5.5$. In order to dope with various $\mathrm{Eu}^{3+}$ ions, the $\mathrm{mol} \%$ of $\mathrm{BaAl}_{2} \mathrm{O}_{4} / \mathrm{CaAl}_{4} \mathrm{O}_{7}$ was kept constant, while the mol\% of $\mathrm{Eu}^{3+}$ was varied at a range of $0 \leq x \leq 5.5 \mathrm{~mol} \%$. All these chemicals were purchased from Sigma-Aldrich and used without further purification. These reagents were weighed and thoroughly mixed in $70 \mathrm{ml}$ of deionized water. The uniformity of oxygen was obtained, because oxidizers such as $\mathrm{Al}\left(\mathrm{NO}_{3}\right)_{3} \cdot 9 \mathrm{H}_{2} \mathrm{O}, \mathrm{Ca}\left(\mathrm{NO}_{3}\right)_{2} \cdot 9 \mathrm{H}_{2} \mathrm{O}$, and $\mathrm{Ba}\left(\mathrm{NO}_{3}\right)_{2} \cdot 9 \mathrm{H}_{2} \mathrm{O}$ decompose to active oxygen at $\sim 150-200$ [24], above 560 [25] and $\sim 600^{\circ} \mathrm{C}$ [26], respectively. However, the solutions were heated at temperatures $\sim 80^{\circ} \mathrm{C}$ for $3 \mathrm{~h}$ under constant stirring using a magnetic stirrer to obtain gels. The gels were dried at room temperature for $12 \mathrm{~h}$ to allow enough gelling. The gels were calcined in a furnace at $1000^{\circ} \mathrm{C}$ for $3.5 \mathrm{~h}$. This is because $\mathrm{CaAl}_{4} \mathrm{O}_{7}$ crystallizes directly at $883^{\circ} \mathrm{C}$ [27]. The product from the furnace was then crushed in an agate mortar with a pestle for powder synthesis. The ground and pulverized powders were taken for characterization using different analysis techniques.

2.2. Sample Characterization. The phase purity and the crystal structure of the phosphors were analyzed by XRD using $\mathrm{CuK} \alpha(\lambda=1.5418 \AA)$ radiation at $40 \mathrm{kV}$ and $40 \mathrm{~mA}$. 
The data was collected using a step scan mode with a step size of $0.01^{\circ}$ and a counting time of $10 \mathrm{~s}$ in the range of $2 \theta$ from $10^{\circ}$ to $80^{\circ}$. The surface structure and the elementary composition were characterized using a Shimadzu Superscan ZU SSX-550 SEM coupled with an energy dispersion spectroscopy (EDS) with an accelerating voltage of $5 \mathrm{kV}$. The particle size was characterized by TEM. The PL spectra and luminescence decay were recorded using Hitachi F-7000 fluorescence spectrometer.

\section{Results and Discussion}

3.1. XRD. The XRD patterns of $\mathrm{CaAl}_{4} \mathrm{O}_{7}, \mathrm{BaAl}_{2} \mathrm{O}_{4}$, and $\mathrm{BC}$ are displayed in Figure 1. The diffraction peaks of $\mathrm{CaAl}_{4} \mathrm{O}_{7}$ and $\mathrm{BaAl}_{2} \mathrm{O}_{4}$ were indexed to the standard pattern of the single-phase monoclinic $\mathrm{CaAl}_{4} \mathrm{O}_{7}$ (JCPDS 076-0706, space group: $\left.\mathrm{C} 2 /_{c}(15)\right)$ and single-phase hexagonal $\mathrm{BaAl}_{2} \mathrm{O}_{4}$ (JCPDS 72-1331, space group: P6322 (182)), respectively. For the $\mathrm{BC}$ pattern, it can be seen that it has both the diffraction peaks of $\mathrm{CaAl}_{4} \mathrm{O}_{7}$ and $\mathrm{BaAl}_{2} \mathrm{O}_{4}$ but resembles more that of the $\mathrm{BaAl}_{2} \mathrm{O}_{4}$ phase. This is because the peaks ascribed to $\mathrm{CaAl}_{4} \mathrm{O}_{7}$ appear weakly in the $\mathrm{BC}$ phase, indicating that there is more $\mathrm{BaAl}_{2} \mathrm{O}_{4}$ powder formed than $\mathrm{CaAl}_{4} \mathrm{O}_{7}$. Figure 2 presents the diffraction peaks of $\mathrm{BC}$ and $\mathrm{Eu}^{3+}$ doped $\mathrm{BC}$ phosphors. However, the $\mathrm{Eu}^{3+}$-doped phosphors show similar diffraction patterns to those of $\mathrm{BC}$ irrespective of the $\mathrm{Eu}^{3+}$ concentration. It is also clear that there are no secondary peaks due to impurities as $\mathrm{Eu}^{3+}$ concentration was varied. Therefore, it can be concluded that the $\mathrm{Eu}^{3+}$ ions were completely incorporated into the matrix of the individual phases.

From the analysis of Figure 1, it appears that the BC phase is composed of two separate phases, namely, the $\mathrm{BaAl}_{2} \mathrm{O}_{4}$ and $\mathrm{CaAl}_{4} \mathrm{O}_{7}$ phases. Therefore, it is important to study the influence of concentration of $\mathrm{Eu}^{3+}$ on each phase in BC. Figures 3(a) and 3(b) show the analysis of the (112) and (311) diffraction peaks of $\mathrm{BaAl}_{2} \mathrm{O}_{4}$ and $\mathrm{CaAl}_{4} \mathrm{O}_{7}$ phases, respectively. In Figure 3(a), the diffraction peak in the (112) direction is chosen for the analysis of the $\mathrm{BaAl}_{2} \mathrm{O}_{4}$ phase. This is because the most intense peak (102) splits. Moreover, the second and third most intense peaks (110) and (100) are aligned with the (131) and (020) peaks of the $\mathrm{CaAl}_{4} \mathrm{O}_{7}$ phase, respectively. Figure 3(a) firstly reveals that, in general, the peak intensities decrease with an increase in $\mathrm{Eu}^{3+}$ concentration when compared to $\mathrm{BaAl}_{2} \mathrm{O}_{4}$ phase. This suggests the loss of crystallinity due to the incorporation of $\mathrm{Eu}^{3+}$ ions $[3,28]$. Secondly, most of the diffraction peaks are shifted to lower angles compared to the $\mathrm{BaAl}_{2} \mathrm{O}_{4}$ phase, which implies an increase in lattice parameters. This observation deviates from Vegard's law. It is expected that when an ion of a smaller radius such as $\mathrm{Ca}^{2+}(=1.12 \AA), \mathrm{Eu}^{3+}(=1.07 \AA)$ or $\mathrm{Al}^{3+}$ $(=0.53 \AA)$ replaces another with larger radius such as $\mathrm{Ba}^{2+}$ $(=1.34 \AA)$, the lattice parameters will decrease $[3,29,30]$. Similar results were obtained by Lubarda [30], King [31], and Motloung et al. [32]. In a study of the lattice parameters of binary alloys, including $\mathrm{Al}-\mathrm{Cu}, \mathrm{Al}-\mathrm{Mg}$, and $\mathrm{Cu}-\mathrm{Fe}$, just to name a few, Lubarda [30] reported that one of the factors that affect the structure and formation of an alloy is the atomic size. The size effect has been often studied from an

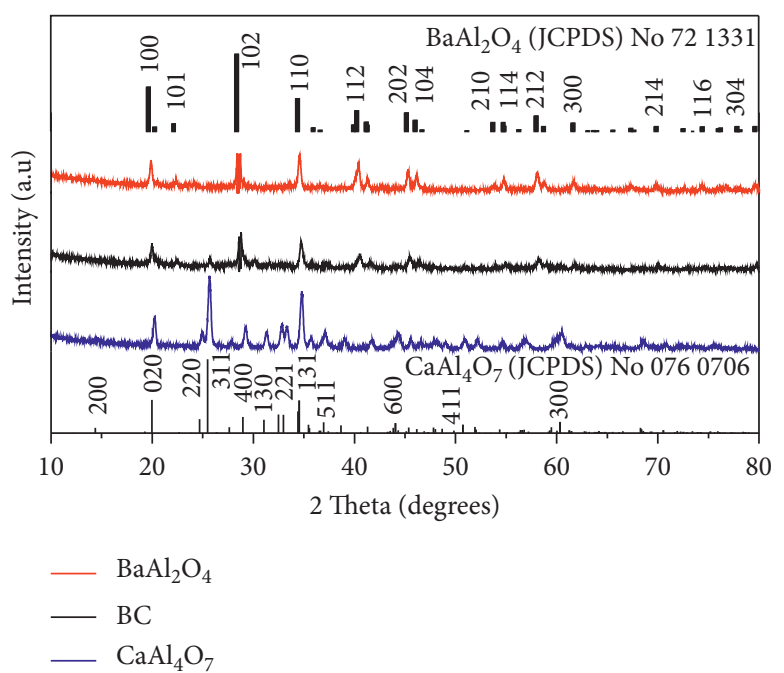

Figure 1: Powder XRD patterns of $\mathrm{BaAl}_{2} \mathrm{O}_{4}, \mathrm{BC}$, and $\mathrm{CaAl}_{4} \mathrm{O}_{7}$ phosphors and the JCPDS cards.

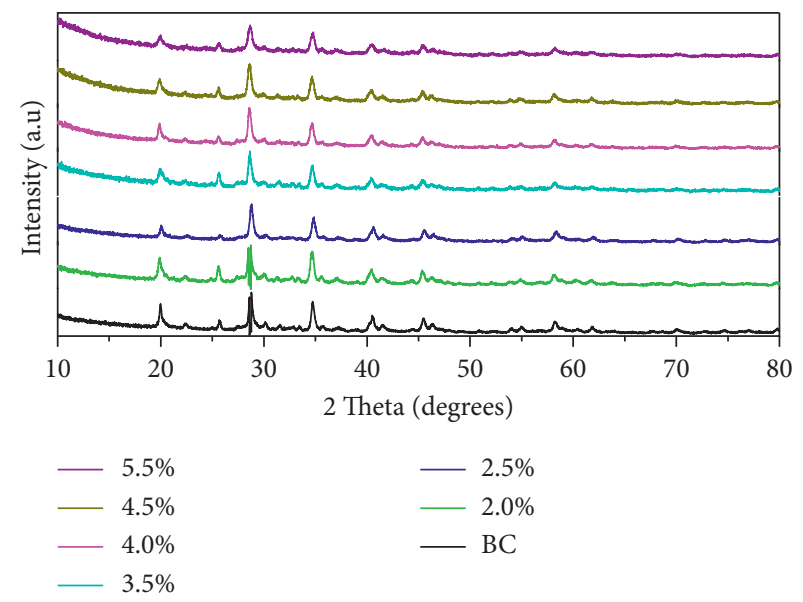

FIgURe 2: Powder XRD patterns of the BC: $x \% \mathrm{Eu}^{3+}(0 \leq x \leq 5.5)$ series.

idealized point of view by methods of continuum elasticity; a solid spherical inclusion is inserted into a spherical hole of a matrix material atom. The size disparity between the solute and solvent atoms causes the volume change of the solution, and this can be related to the effective lattice parameter $[30,31]$. The continuum elasticity model has a limited success. This is because it is based on complex topics such as quantum mechanics and physical chemistry. The electronic interactions between the outermost quantum shells of the solute and the solvent depend on their electrochemical characteristics, partially reflected by their positions in the periodic table of elements, and are far too complex to be accounted for only by a simple size factor. Therefore, for certain alloy systems, this has led to good results, but, in many cases, the predicted lattice spacing was not correct [30]. In a similar study involving $\mathrm{Al}-\mathrm{Cu}, \mathrm{Si}-\mathrm{Ge}$, and $\mathrm{Ag}-\mathrm{Au}$, it was observed that, for the alloys in which the solute atom is smaller than that of the solvent, the sign of 


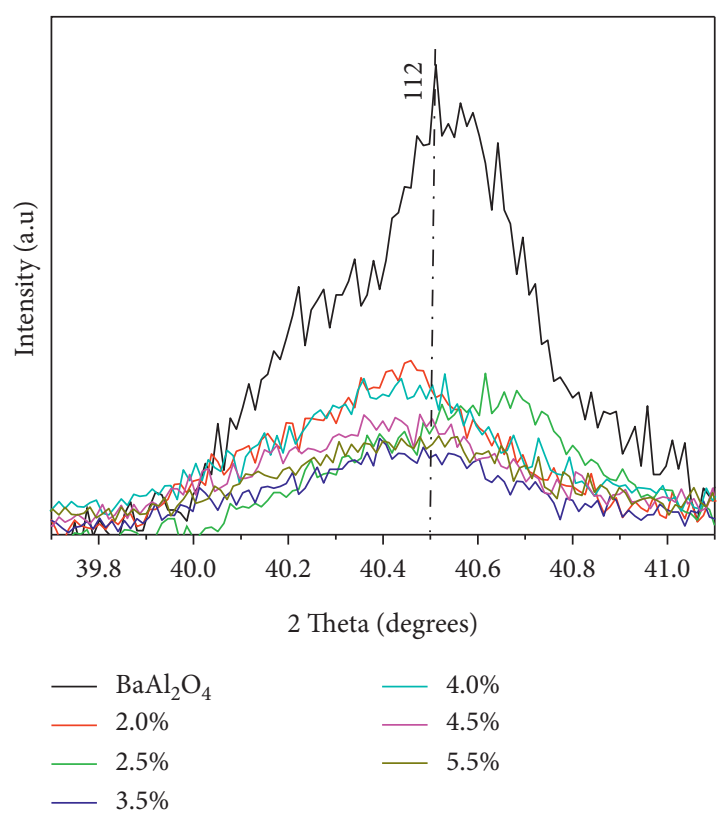

(a)

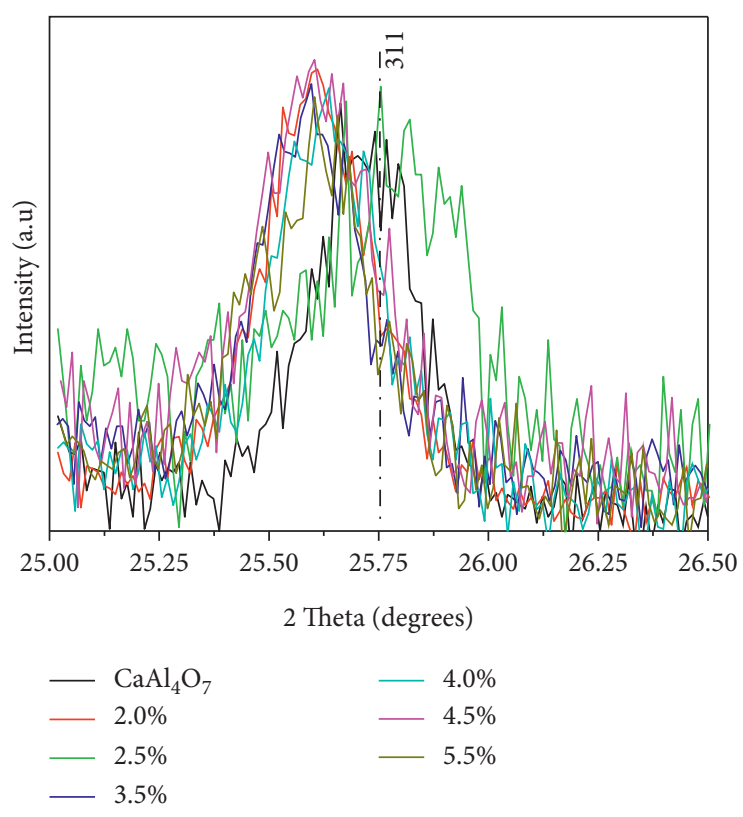

(b)

FIGURE 3: Examination of the peaks for BC and BC: $x \% \mathrm{Eu}^{3+}(0 \leq x \leq 5.5)$ in the (a) (112) direction and (b) (311) direction.

the predicted change in atomic volume was always found to be in error. It was suggested that the tendency of a metallic solid to deviating from Vegard's law might be taken as a measure of modification of the electronic environment of the solute atom [31]. In the study of $\mathrm{ZnAl}_{2} \mathrm{O}_{4}: x \% \mathrm{~Pb}^{2+}$, the deviation was attributed to the shrinking of the $\mathrm{Pb}^{2+}$ ion outer electron shell due to its electronic interaction $[32,33]$. However, for $x=3.5$ and 5.5 , there seems to be no substitution between $\mathrm{Eu}^{3+}, \mathrm{Ca}^{2+}$, and $\mathrm{Ba}^{2+}$ for the $\mathrm{BaAl}_{2} \mathrm{O}_{4}$ phase, since there is no shift in the diffraction angle when compared to the $\mathrm{BaAl}_{2} \mathrm{O}_{4}$ phase. For $x=2.5$, the diffraction peak has shifted to higher angle, suggesting that $\mathrm{Eu}^{3+}$ and/ or $\mathrm{Ca}^{2+}$ have replaced $\mathrm{Ba}^{2+}$ in the $\mathrm{BaAl}_{2} \mathrm{O}_{4}$ phase leading to the decrease in the lattice parameters $[20,34]$. Figure $3(\mathrm{~b})$ displays the most intense diffraction peaks of $\mathrm{CaAl}_{4} \mathrm{O}_{7}$ phase in the (311) direction. It shows that the peak intensities have increased when compared to the $\mathrm{CaAl}_{4} \mathrm{O}_{7}$ phase. This indicates that doping the samples with $\mathrm{Eu}^{3+}$ has improved crystallinity. It also reveals that the diffraction peaks have shifted to lower angles, suggesting that $\mathrm{Ba}^{2+}$ has substituted $\mathrm{Ca}^{2+}$ in the $\mathrm{CaAl}_{4} \mathrm{O}_{7}$ phase, leading to the increase in the lattice parameters. For $x=2.5$, there is a higher shift in the (311) diffraction angle, indicating that $\mathrm{Eu}^{3+}$ has substituted $\mathrm{Ca}^{2+}$, leading to the decrease in the lattice parameters $[35,36]$. It is noteworthy to indicate that, due to the large difference between the atomic radii of $\mathrm{Al}^{3+}$ and the other ions, namely, $\mathrm{Ba}^{2+}, \mathrm{Eu}^{3+}$, and $\mathrm{Ca}^{2+}$, it is unlikely that $\mathrm{Al}^{3+}$ would substitute those ions. Therefore, the ions $\mathrm{Ba}^{2+}, \mathrm{Eu}^{3+}$, and $\mathrm{Ca}^{2+}$ can substitute each other due to the slight difference between their atomic radii. Formulae (1) and (2) were used to estimate the lattice parameters of the hexagonal and monoclinic crystals, respectively.

$$
\begin{aligned}
& \left(\frac{1}{d_{h k l}}\right)^{2}=\frac{4}{3}\left(\frac{h^{2}+h k+k^{2}}{a^{2}}\right)+\frac{l^{2}}{c^{2}}, \\
& \left(\frac{1}{d_{h k l}}\right)^{2}=\frac{h^{2}}{a^{2}}+\frac{k^{2}}{b^{2}}+\frac{l^{2}}{c^{2}}, \quad\left(\gamma=90^{\circ}\right),
\end{aligned}
$$

where $a, b$, and $c$ are the lattice parameters, $d$ is the interplanar distance, and $h k l$ are the Miller indices. Crystal planes such as (112) and (311) were used to calculate the lattice parameters of the $\mathrm{BaAl}_{2} \mathrm{O}_{4}$ and $\mathrm{CaAl}_{4} \mathrm{O}_{7}$ nanocrystals, respectively. The results obtained are displayed in Table 1.

The well-known Scherrer's formula [35] given in equation (3) was used to estimate the crystallite size of the prepared samples.

$$
D=\frac{0,9 \lambda}{\beta \cos \theta},
$$

where $D$ is the crystallite size $(\mathrm{nm}), \lambda$ is the wavelength $(0.15406 \mathrm{~nm}), \beta$ is the full width at half maximum (FWHM) (radians), and $\theta$ is the angle of diffraction (degrees).

The calculated crystallite sizes for each component phase in $\mathrm{BC}$ are displayed in Table 2. Figure 4(a) shows the variation of crystallite sizes with $x \% \mathrm{Eu}^{3+}$. It can be seen that the crystallite size is influenced by concentration, even though it fluctuates as $x \% \mathrm{Eu}^{3+}$ increases. It is not clear as why the two phases follow almost the same trend. However, it is noteworthy to indicate that at least three ions $\mathrm{Ca}^{2+}, \mathrm{Ba}^{2+}$, and $\mathrm{Eu}^{3+}$ are substituting each other in BC. Therefore, the crystallite size may also be influenced by the amount of $\mathrm{Ca}^{2+}$ or $\mathrm{Ba}^{2+}$ ions in the $\mathrm{BaAl}_{2} \mathrm{O}_{4}$ and $\mathrm{CaAl}_{4} \mathrm{O}_{7}$ phase, respectively. The dislocation densities of the samples were estimated from the well-known Taylor relationship [37]: 
TABLE 1: Summary of the samples identification and lattice parameters.

\begin{tabular}{|c|c|c|c|c|c|}
\hline \multirow{2}{*}{ Sample ID } & \multicolumn{2}{|c|}{$112-\mathrm{BaAl}_{2} \mathrm{O}_{4}$} & \multicolumn{3}{|c|}{$311-\mathrm{CaAl}_{4} \mathrm{O}_{7}$} \\
\hline & $a(\mathrm{~nm})$ & $b=c(\mathrm{~nm})$ & $a(\mathrm{~nm})$ & $b(\mathrm{~nm})$ & $c(\mathrm{~nm})$ \\
\hline $\mathrm{BaAl}_{2} \mathrm{O}_{4}$ & 0.4290 & 1.3029 & - & - & - \\
\hline $\mathrm{CaAl}_{4} \mathrm{O}_{7}$ & - & - & 0.9420 & 1.4877 & 0.4504 \\
\hline $2.0 \%$ & 0.4292 & 1.4755 & 0.8978 & 1.5222 & 0.4460 \\
\hline $2.5 \%$ & 0.4283 & 0.9770 & 0.9678 & 1.4877 & 0.4504 \\
\hline $3.5 \%$ & 0.4292 & 1.4755 & 1.0489 & 1.4640 & 0.4600 \\
\hline $4.0 \%$ & 0.4292 & 1.4755 & 0.9678 & 1.4877 & 0.4504 \\
\hline $4.5 \%$ & 0.4292 & 1.4755 & 0.9678 & 1.4877 & 0.4504 \\
\hline $5.5 \%$ & 0.4292 & 1.4755 & 0.9678 & 1.4877 & 0.4504 \\
\hline
\end{tabular}

TABLE 2: Crystallite size (D) (nm) and dislocation $(\delta)\left(\mathrm{nm}^{-2}\right)$ of the different phases in BC.

\begin{tabular}{lcccc}
\hline Sample ID & 112 of $\mathrm{BaAl}_{2} \mathrm{O}_{4}(\mathrm{D})$ & 311 of $\mathrm{CaAl}_{4} \mathrm{O}_{7}(\mathrm{D})$ & $\delta\left(112-\mathrm{BaAl}_{2} \mathrm{O}_{7}\right) \times 10^{-3}$ & $\delta\left(311-\mathrm{CaAl}_{4} \mathrm{O}_{7}\right) \times 10^{-3}$ \\
\hline $\mathrm{BC}$ & 18 & 33 & 3.1 & 1.0 \\
$2.0 \%$ & 17 & 23 & 3.5 & 1.9 \\
$2.5 \%$ & 16 & 29 & 3.9 & 1.2 \\
$3.5 \%$ & 17 & 19 & 3.1 & 2.8 \\
$4.0 \%$ & 18 & 30 & 3.9 & 2.1 \\
$4.5 \%$ & 16 & 22 & 3.9 & 2.5 \\
$5.5 \%$ & 16 & 20 & & \\
\hline
\end{tabular}

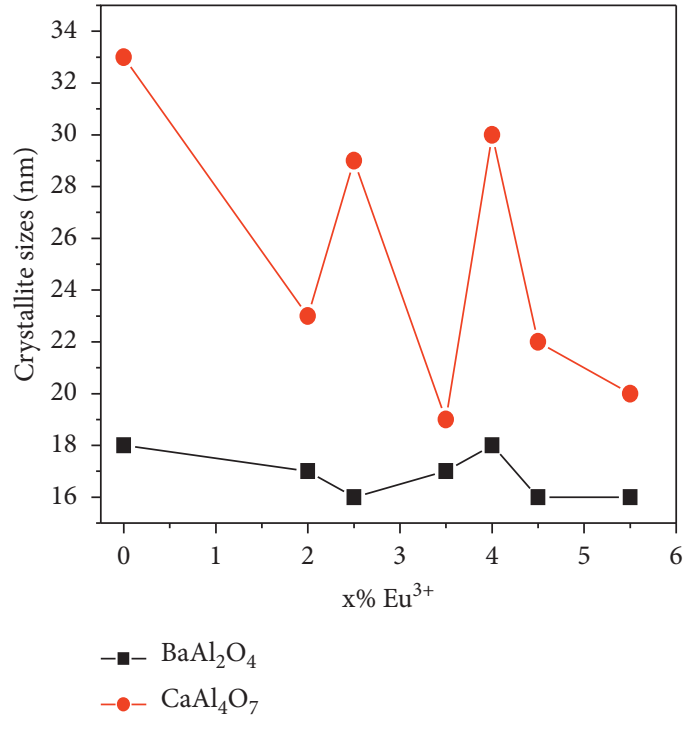

(a)

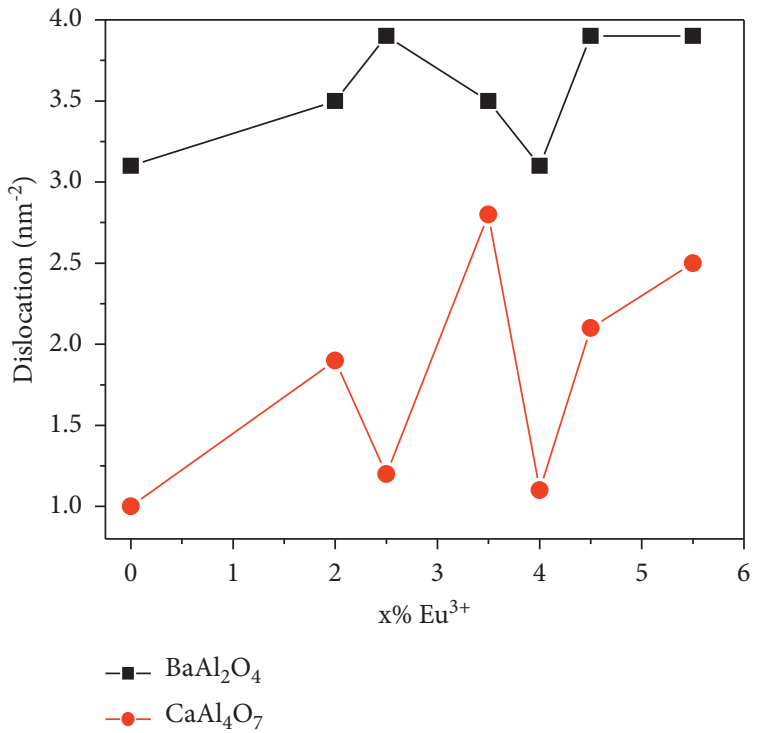

(b)

Figure 4: (a) Crystallite sizes versus $x \% \mathrm{Eu}^{3+}$ and (b) dislocation versus $x \% \mathrm{Eu}^{3+}$.

$$
\delta=\frac{1}{D^{2}}
$$

where $D$ is the average crystallite size $(\mathrm{nm})$ and $\delta$ is the dislocation density $\left(\mathrm{nm}^{-2}\right)$. The results are displayed in Table 2. Figure 4(b) displays the density of dislocation versus $x \% \mathrm{Eu}^{3+}$. It can be seen that the dislocation fluctuates as the concentration of the dopants increases in the $\mathrm{BaAl}_{2} \mathrm{O}_{4}$ and $\mathrm{CaAl}_{4} \mathrm{O}_{7}$ phase. However, it was anticipated that the dislocation would increase with increasing concentration of the dopants due to the lattice mismatch between the foreign atoms and those in $\mathrm{BaAl}_{2} \mathrm{O}_{4}$ and $\mathrm{CaAl}_{4} \mathrm{O}_{7}$ phase. This is because as $x \% \mathrm{Eu}^{3+}$ increases, stress should increase in the crystal lattice and suppress the growth of nanocrystals [23]. Consequently, dislocation increases. Therefore, it is not clear why dislocation fluctuates as $x \% \mathrm{Eu}^{3+}$ increases.

3.2. SEM. The SEM study was carried out to analyze the surface morphology of the synthesized nanophosphor powders. Figure 5(a) depicts the $\mathrm{BaAl}_{2} \mathrm{O}_{4}$ phase, which showed nanorod-like structures unevenly grown on smooth 


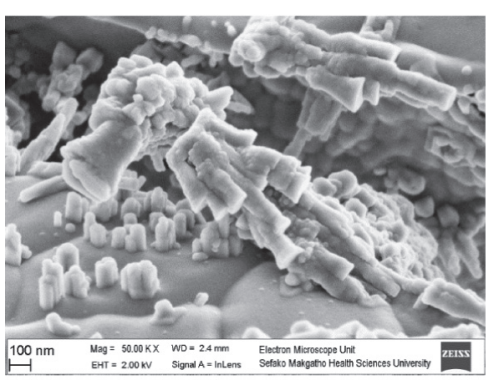

(a)

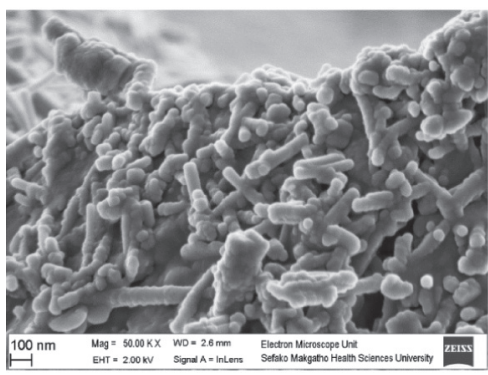

(d)

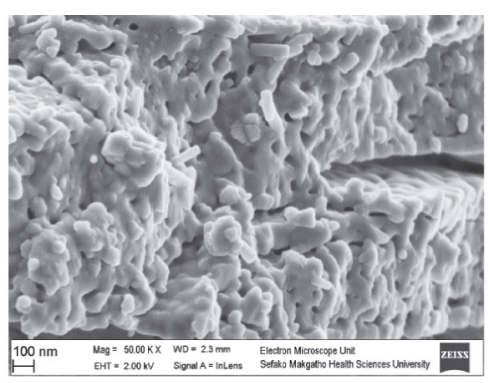

(b)

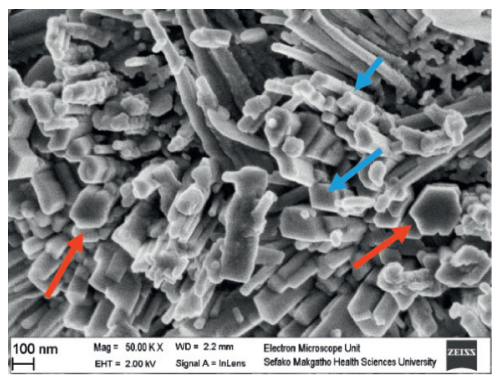

(e)

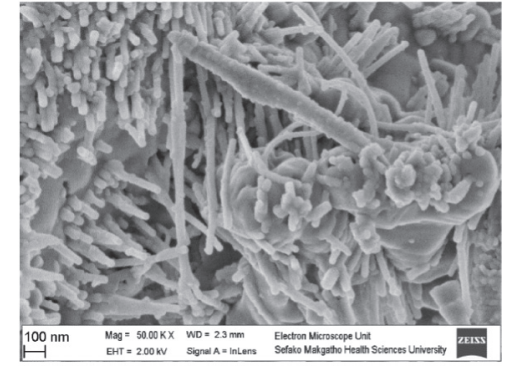

(c)

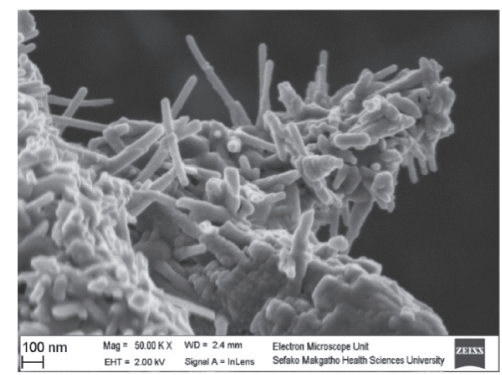

(f)

Figure 5: SEM images for (a) $\mathrm{BaAl}_{2} \mathrm{O}_{4}$, (b) $\mathrm{CaAl}_{4} \mathrm{O}_{7}$, (c) $\mathrm{BC}$, (d) $x=2$, (e) $x=3.5$, and (f) $x=5.5$.

hexagonal seed layers. The cluster nature of the nanorods could be the result of poor dissolution of these nanorods [38]. Figure 5(b) represents the $\mathrm{CaAl}_{4} \mathrm{O}_{7}$ phase, which showed a homogeneous rough surface with pores created by escaping gases during crystallization [11,39]. Figure 5(c) represents the $\mathrm{BC}$ phase; a different morphology from the ones in Figures 5(a) and 5(b) can be seen. However, this morphology seems to resemble the combination or mixture of both $\mathrm{CaAl}_{4} \mathrm{O}_{7}$ and $\mathrm{BaAl}_{2} \mathrm{O}_{4}$ observed in Figures 5(a) and 5 (b). The surface is covered with bud-like nanorods and nanowires. The $x=2$ sample is shown in Figure 5(d); it can be seen that the nanorods and nanowires observed in Figure 5(c) have grown bigger in width. Figure 5(e) represents the $x=3.5$ sample, in a mixture of hexagonal (indicated with red arrows) and monoclinic (indicated with blue arrows) nanorods and nanowires. The nanorods and nanowires have grown much bigger and they are vertically aligned. Figure 5(f), which shows the $x=5.5$ sample, clearly exhibits the homogeneous distribution of rod-like structures resembling the ones observed in Figures 5(c) and 5(d). Therefore, the SEM and XRD studies seem to be supporting each other, since it is very clear that the $\mathrm{Eu}^{3+}$ concentration influences the morphology of the prepared samples.

3.3. TEM. Some of the prepared samples (BC and $x=3.5$ ) were analyzed by TEM; Figure 6(a) depicts the BC phase that reveals the growth of nanocrystals on a smooth surface. The size of the nanocrystals varies from a few 10 to around $100 \mathrm{~nm}$. Figure 6(b) presents the TEM image of the $x=3.5$ sample. The blue arrows indicate monoclinic nanocrystals with average size varying from 18 to $30 \mathrm{~nm}$. The red arrows indicate hexagonal nanocrystals with average sizes from a few 10 to $100 \mathrm{~nm}$. These results support the calculated crystallite sizes shown in Table 2, using Scherrer's formula.

Figures 6(c) and 6(d) show the typical high-resolution TEM image of the monoclinic and hexagonal crystals, respectively. The spacing of the lattice planes in Figure 6(c) is $0.75 \mathrm{~nm}$, which is consistent with the (020) lattice plane of the monoclinic $\mathrm{CaAl}_{4} \mathrm{O}_{7}\left(\mathrm{~d}_{020}=0.744 \mathrm{~nm}\right)$. The lattice space in Figure $6(\mathrm{~d})$ is $0.38 \mathrm{~nm}$, which corresponds to the (100) lattice planes of the hexagonal $\mathrm{BaAl}_{2} \mathrm{O}_{4}\left(d_{100}=0.372 \mathrm{~nm}\right)$. The slight increase in the lattice spacing has been discussed in Section 3.1. It can be seen that the nanorods are actually hexagonal and monoclinic crystalline grains.

3.4. PL. Figure $7(\mathrm{a})$ shows the excitation and emission spectra of the $\mathrm{BaAl}_{2} \mathrm{O}_{4}, \mathrm{CaAl}_{4} \mathrm{O}_{7}$, and $\mathrm{BC}$ phases, which unveil that all undoped materials have similar excitation and emission bands. It can be seen that BC exhibits higher luminescence intensity than the other two undoped materials, namely, $\mathrm{BaAl}_{2} \mathrm{O}_{4}$ and $\mathrm{CaAl}_{4} \mathrm{O}_{7}$. This may be due to the former having better crystallinity. When monitoring the emission at $436 \mathrm{~nm}$, the results revealed that there is only one excitation peak at $294 \mathrm{~nm}$. This excitation peak is ascribed to intrinsic intraband gap defects such as oxygen vacancies located at different energy levels within the BC phase [20]. When monitoring the excitation at $294 \mathrm{~nm}$, the results unveil one emission peak located around $436 \mathrm{~nm}$ with a shoulder at $460 \mathrm{~nm}$. The emission peak and its shoulder are assigned to the intrinsic intraband gap defects within the undoped materials. This is because the crystallization process can induce defects, which trap electrons and holes [13]. Similar results were obtained by Emen et al. [13] and they have argued that, in a barium aluminate host, the excitation and 


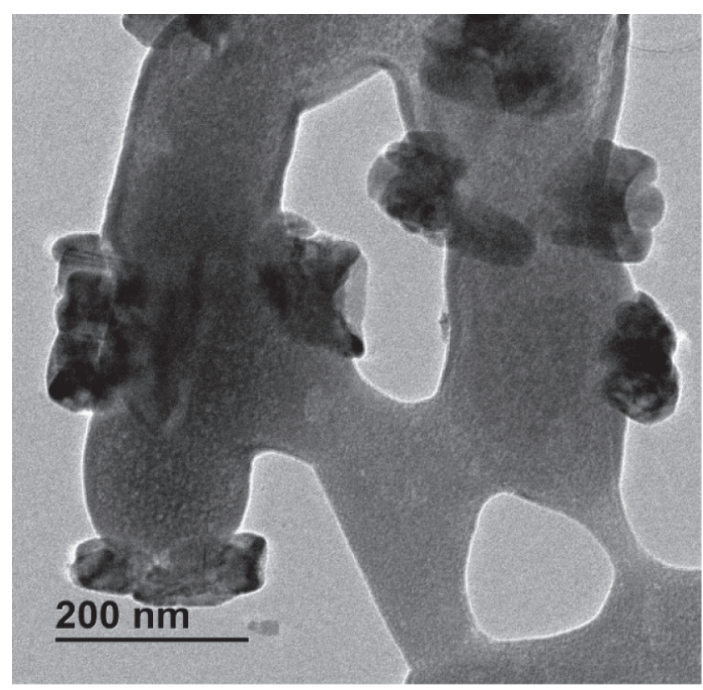

(a)

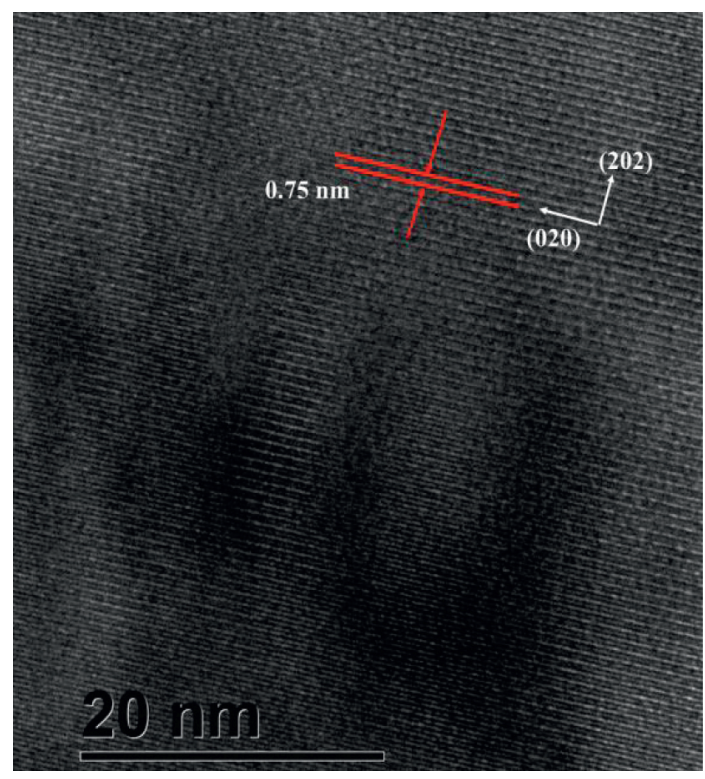

(c)

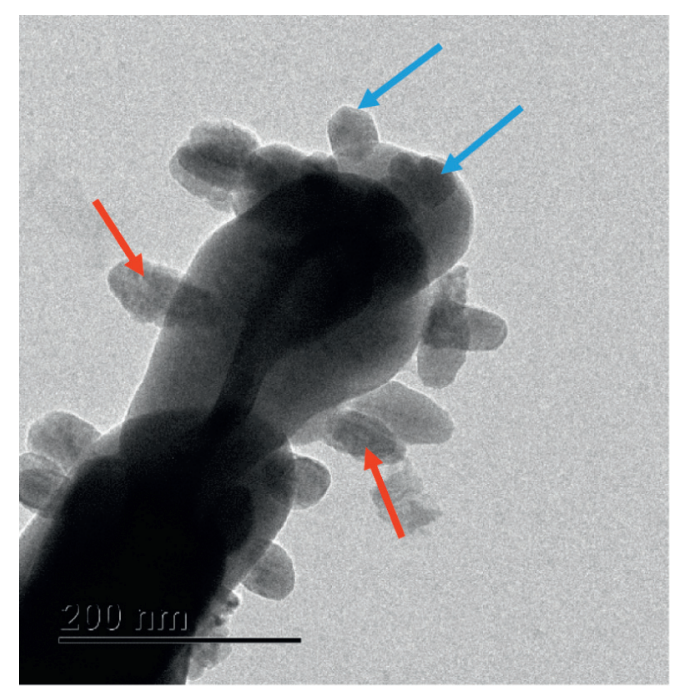

(b)

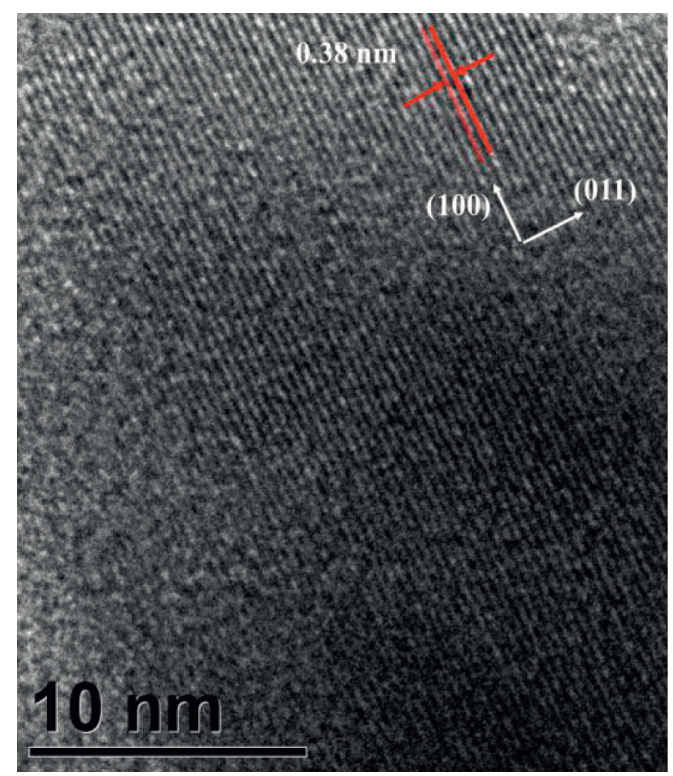

(d)

Figure 6: TEM images of (a) BC and (b) HR-TEM images of (c) (020) plane of monoclinic $\mathrm{CaAl}_{4} \mathrm{O}_{7}$ and (d) (100) plane of hexagonal $\mathrm{BaAl}_{2} \mathrm{O}_{4}$.

emission peaks could be a result of native defects such as cation and anion vacancies in the host crystal. Moreover, Ziyauddin et al. [39] found that oxygen vacancies and three different sites of calcium vacancies are present in calcium aluminate (host). Furthermore, the PL emission of BC is asymmetrical, which supports the presence of more than one cation site involved in the emission [37]. Figure 7(b) shows the deconvolution of the BC PL emission spectrum excited at $294 \mathrm{~nm}$. It reveals that the Gaussian-multicurve fit of the PL emission of BC at around $436 \mathrm{~nm}$ (blue fit) and $460 \mathrm{~nm}$ (green fit) fits match very well with the experimental curve. This confirms the presence of at least two radiative defects in the $\mathrm{BC}$ phase as discussed in Figure 7(a). Figure 7(c) shows the excitation and the emission spectra for the BC: $x \% \mathrm{Eu}^{3+}$ $(0 \leq x \leq 5.5)$ series. The excitation spectra were recorded at around $294 \mathrm{~nm}$ by monitoring the violet emission at $436 \mathrm{~nm}$. The emission spectra show four bands around 436 with a shoulder at around 460, 616 with a shoulder at 590, and 656 and $703 \mathrm{~nm}$ when the material is excited at $294 \mathrm{~nm}$. The emission peak at $436 \mathrm{~nm}$ with its shoulder at around $460 \mathrm{~nm}$ is also observed in the undoped $\mathrm{BC}$ matrix. Their presence in the $\mathrm{BC}$ matrix as well as the $\mathrm{BC}: x \% \mathrm{Eu}^{3+}$ confirms that the emissions are originated from the native defects in the $\mathrm{BC}$ matrix. The shoulder at $590 \mathrm{~nm}$ is assigned to ${ }^{5} \mathrm{D}_{0} \longrightarrow{ }^{7} \mathrm{~F}_{1}$ of $\mathrm{Eu}^{3+}$ and the emission peaks at 616,656 , and $703 \mathrm{~nm}$ are assigned to the ${ }^{5} \mathrm{D}_{0} \longrightarrow{ }^{7} \mathrm{~F}_{2},{ }^{5} \mathrm{D}_{0} \longrightarrow{ }^{7} \mathrm{~F}_{3}$, and ${ }^{5} \mathrm{D}_{0} \longrightarrow{ }^{7} \mathrm{~F}_{4}$ transitions of $\mathrm{Eu}^{3+}$, respectively [9]. This shows that $\mathrm{Eu}^{3+}$ has introduced many new excitation bands in the ultraviolet and visible regions. These excitation bands are ascribed to the different oxygen vacancy pairs behavior induced by 


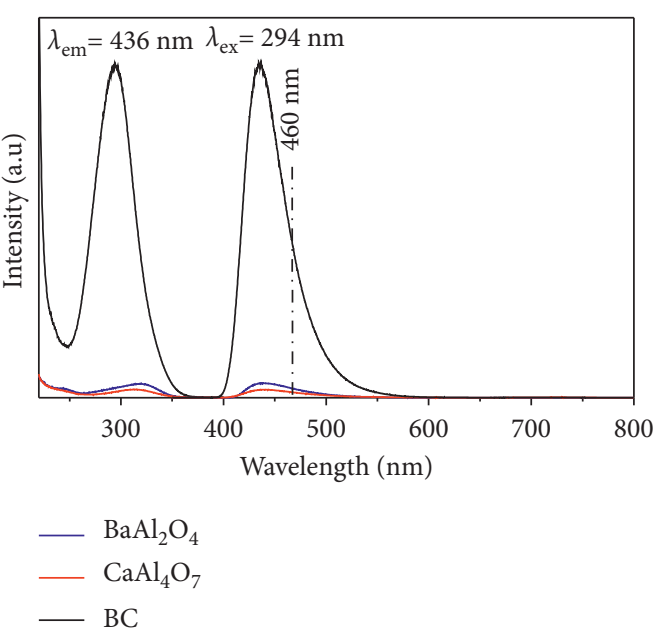

(a)

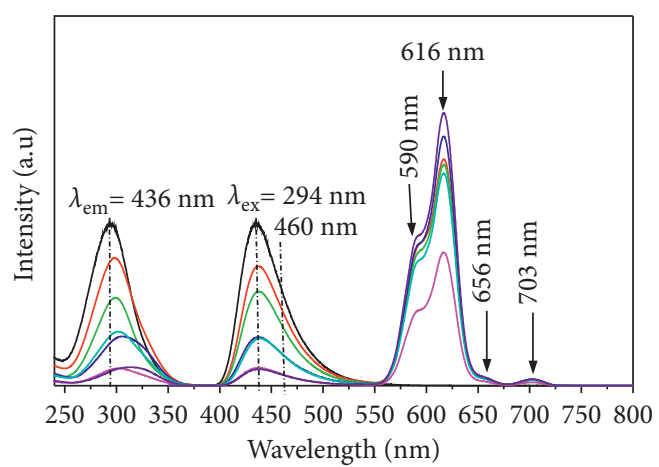

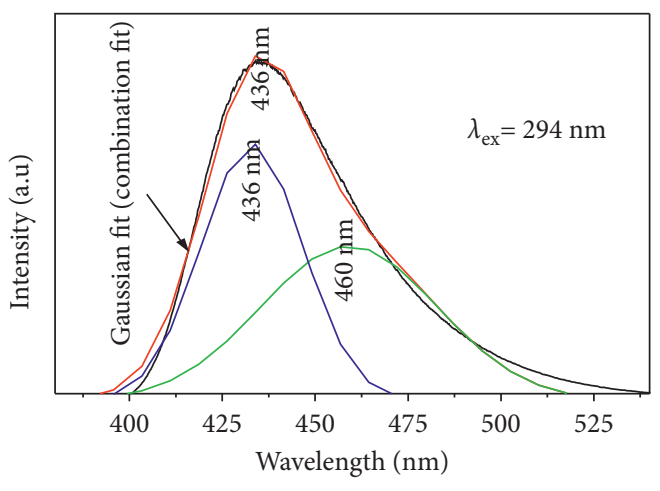

$-\mathrm{BC}$
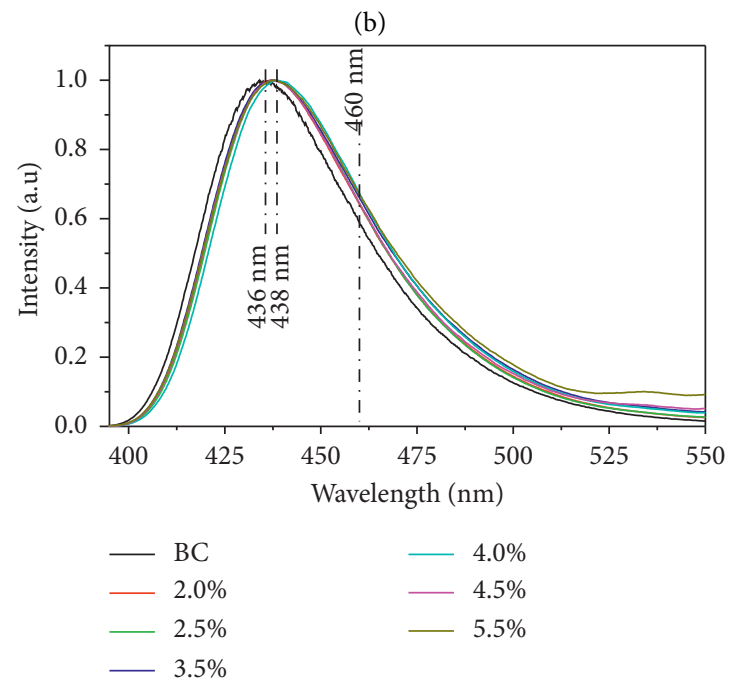

(d)

(c)

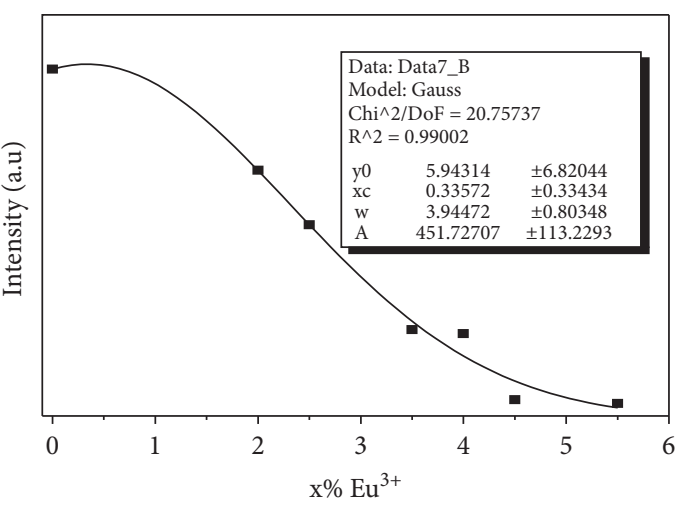

- Experimental

— Gaussian fit

(e)

Figure 7: (a) Excitation and emission spectra of $\mathrm{CaAl}_{2} \mathrm{O}_{4}, \mathrm{BaAl}_{2} \mathrm{O}_{4}$, and $\mathrm{BC}$, (b) the deconvolution of $\mathrm{BC}$ spectrum, (c) excitation and emission spectra of BC: $x \% \mathrm{Eu}^{3+}(0 \leq x \leq 5.5)$, (d) the normalized emission spectra of BC: $x \% \mathrm{Eu}^{3+}(0 \leq x \leq 5.5)$, and (e) the emission intensity of $\mathrm{BC}: x \% \mathrm{Eu}^{3+}$ versus $x \% \mathrm{Eu}^{3+}(0 \leq x \leq 5.5)$.

occupation of the different cation sites [38]. Furthermore, due to the difference between ionic radii of $\mathrm{Eu}^{3+}, \mathrm{Ca}^{2+}$, and $\mathrm{Ba}^{2+}$, when $\mathrm{Eu}^{3+}$ substitutes $\mathrm{Ca}^{2+}$ and/or $\mathrm{Ba}^{2+}$, the symmetry at micro level and the crystal field experienced by $\mathrm{Eu}^{3+}$ may change [15]. These findings are supported by Jia et al. [7] who reported that, in barium aluminate host, there are two $\mathrm{Ba}^{2+}$ 


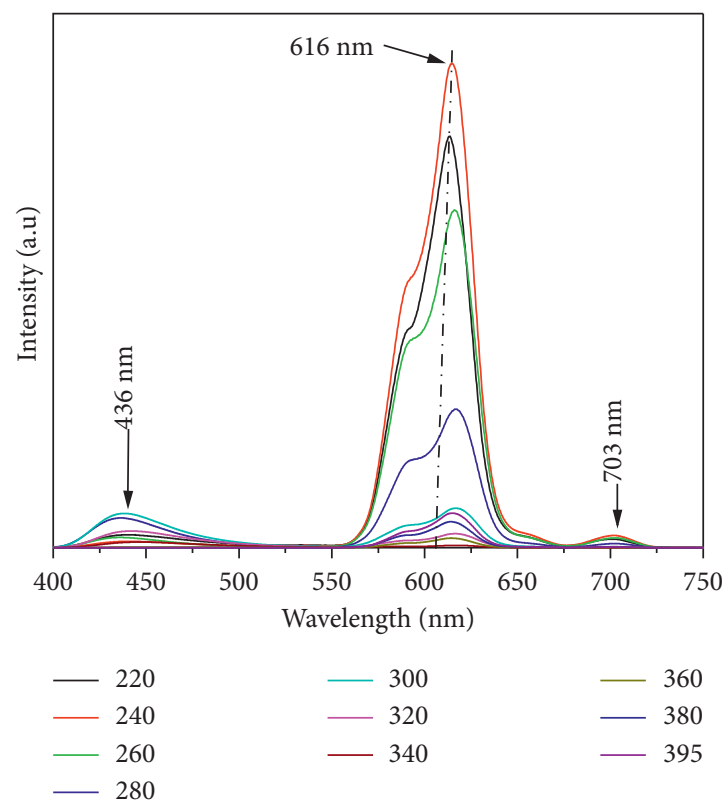

FIGURE 8: Emission spectra of BC: $2 \% \mathrm{Eu}^{3+}$ excited at various wavelengths.

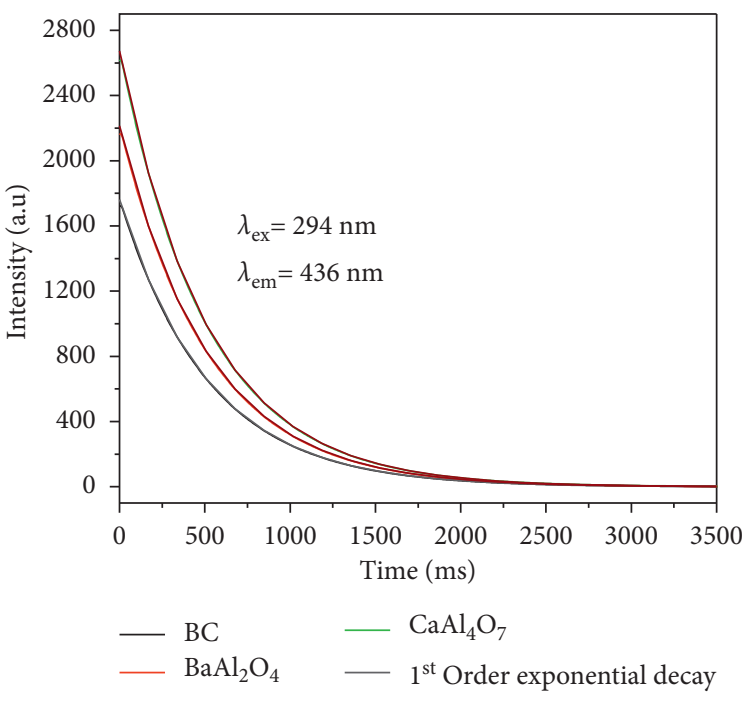

(a)

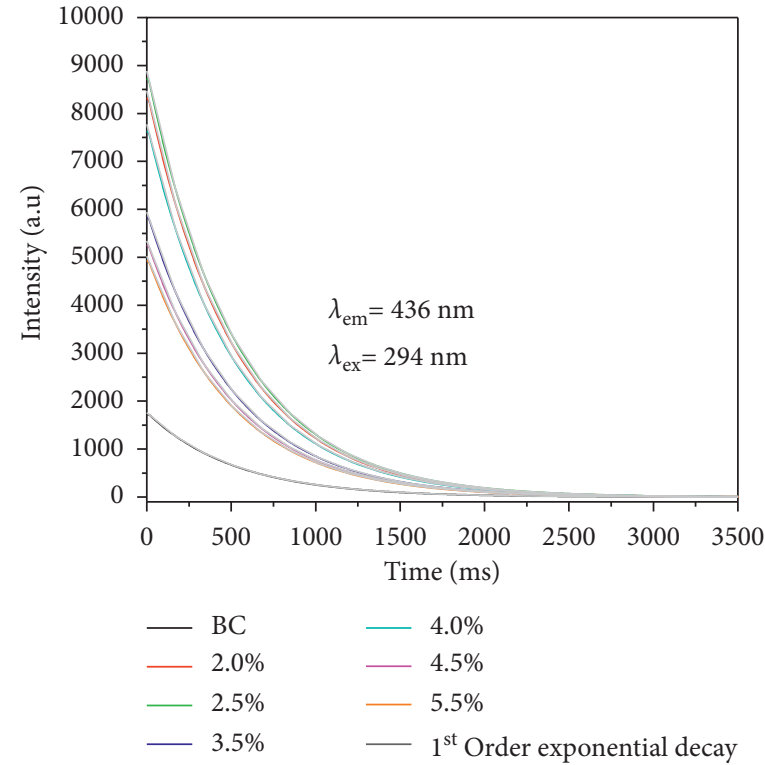

(b)

Figure 9: Decay curves of $\mathrm{Eu}^{3+}$ emission monitored at $436 \mathrm{~nm}$ for (a) $\mathrm{BaAl}_{2} \mathrm{O}_{4}, \mathrm{CaAl}_{4} \mathrm{O}_{7}, \mathrm{BC}$, and (b) $\mathrm{BC}$ : $x \% \mathrm{Eu}^{3+}(0 \leq x \leq 5.5)$ nanophosphors under excitation at $294 \mathrm{~nm}$.

sites with average bond distance $\mathrm{Ba}-\mathrm{O}$ that equals 2.85 and $2.94 \AA$, respectively. Thus, the ligand field strength at one site is expected to be weaker than that of the other site, leading to different emission intensities. It was also reported by Shannon et al. [40] that there are two types of $\mathrm{Ca}-\mathrm{O}$ sites in $\mathrm{CaAl}_{2} \mathrm{O}_{4}$ whose average distances are 2.4 and $2.8 \AA$ for the shorter and longer one, respectively. However, only the longer distance has enough space for an $\mathrm{Eu}^{3+}$ ion, which suggests that $\mathrm{Eu}^{3+}$ could substitute at least three different sites in $\mathrm{BC}: x \% \mathrm{Eu}^{3+}$, resulting in the enhancement of the emission intensity. Moreover, the presence of the strongest peak at $616 \mathrm{~nm}$ suggests that the ${ }^{5} \mathrm{D}_{0} \longrightarrow{ }^{7} \mathrm{~F}_{2}$ electronic dipole transition is dominant. Therefore, the site does not have inversion symmetry [3]. To investigate the origination of the emission peaks of the prepared nanophosphors, the normalized emission spectrum is displayed in Figure $7(\mathrm{~d})$. It confirms the presence of the emission peak at 436 and its shoulder at around $460 \mathrm{~nm}$ as discussed in Figures 7(b) and 7 (c). There is a slight shift in the emission peak of the doped samples to a higher wavelength, at around $438 \mathrm{~nm}$. This could be attributed to the shrinkage of BC's crystal lattice as compared to the $\mathrm{BaAl}_{2} \mathrm{O}_{4}$ and $\mathrm{CaAl}_{4} \mathrm{O}_{7}$ phases. As a result, 
TABLE 3: Kinetic analysis results and CIE $(x ; y)$ coordinates for $\mathrm{BaAl}_{2} \mathrm{O}_{4}, \mathrm{CaAl}_{4} \mathrm{O}_{7}$, and $\mathrm{BC}: x \% \mathrm{Eu}^{3+}(0 \leq x \leq 5.5)$.

\begin{tabular}{lccr}
\hline Samples & $A_{1}$ & $\tau_{1}(\mathrm{~ms})$ & CIE $(x ; y)$ \\
\hline $\mathrm{BC}$ & $1762.1 \pm 0.3$ & $518.8 \pm 0.1$ & $(0.156 ; 0.048)$ \\
$\mathrm{CaAl}_{4} \mathrm{O}_{7}$ & $2675.3 \pm 1.1$ & $514.7 \pm 0.3$ & $(0.211 ; 0.247)$ \\
$\mathrm{BaAl}_{2} \mathrm{O}_{4}$ & $2217.2 \pm 1.3$ & $519.3 \pm 0.4$ & $(0.174 ; 0.130)$ \\
$2.0 \%$ & $8477.9 \pm 1.0$ & $517.4 \pm 0.1$ & $(0.583 ; 0.342)$ \\
$2.5 \%$ & $8894.5 \pm 1.4$ & $521.5 \pm 0.1$ & $(0.578 ; 0.296)$ \\
$3.5 \%$ & $5949.5 \pm 1.0$ & $514.6 \pm 0.1$ & $(0.588 ; 0.347)$ \\
$4.0 \%$ & $7777.2 \pm 0.9$ & $514.7 \pm 0.1$ & $(0.558 ; 0.322)$ \\
$4.5 \%$ & $5344.7 \pm 0.6$ & $516.4 \pm 0.1$ & $(0.580 ; 0.342)$ \\
$5.5 \%$ & $5025.9 \pm 0.6$ & $515.9 \pm 0.1$ & $(0.563 ; 0.330)$ \\
\hline
\end{tabular}

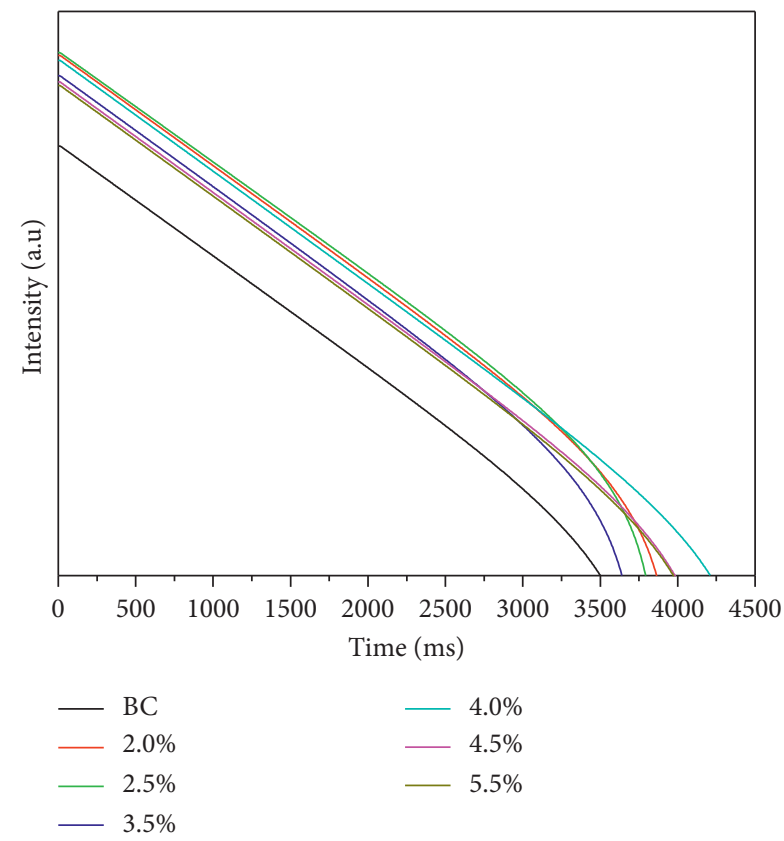

FIGURE 10: Logarithmic decay curves of BC: $x \% \mathrm{Eu}^{3+}(0 \leq x \leq 5.5)$.

the crystal field becomes larger and the emission energy is reduced [41]. To further investigate the emission behavior, Figure 7(e), which shows the emission intensity versus $x \%$ $\mathrm{Eu}^{3+}$, was conducted. It can be seen that the emission intensity decreases as $x \% \mathrm{Eu}^{3+}$ increases within $0.5 \leq x \leq 5.5$. It is also revealed that the optimum concentration is around $0.5 \% \mathrm{Eu}^{3+}$. A further increase in concentration of the dopant $\left(\mathrm{Eu}^{3+}\right)$ results in reduced luminescence. This is due to concentration quenching caused by the migration of excitation energy from one activator center to another which acts as an energy sink [42]. In addition, the graph shows a slight increase within $0 \leq x \leq 0.5$, indicating that if a study is conducted in the range of $0 \leq x \leq 1$, a full Gaussian fit will be obtained. Figure 8 represents the emission intensity versus wavelength for the sample with the most intense peak (BC: $2 \%$ $\left.\mathrm{Eu}^{3+}\right)$. It can be seen that the peaks look the same as in Figure 7(b). Therefore, these peaks are assigned to the same origination as discussed above in Figure 7(b). The optimum excitation wavelength was at $300 \mathrm{~nm}$, which is very close to the $294 \mathrm{~nm}$ wavelength used to excite the samples in this

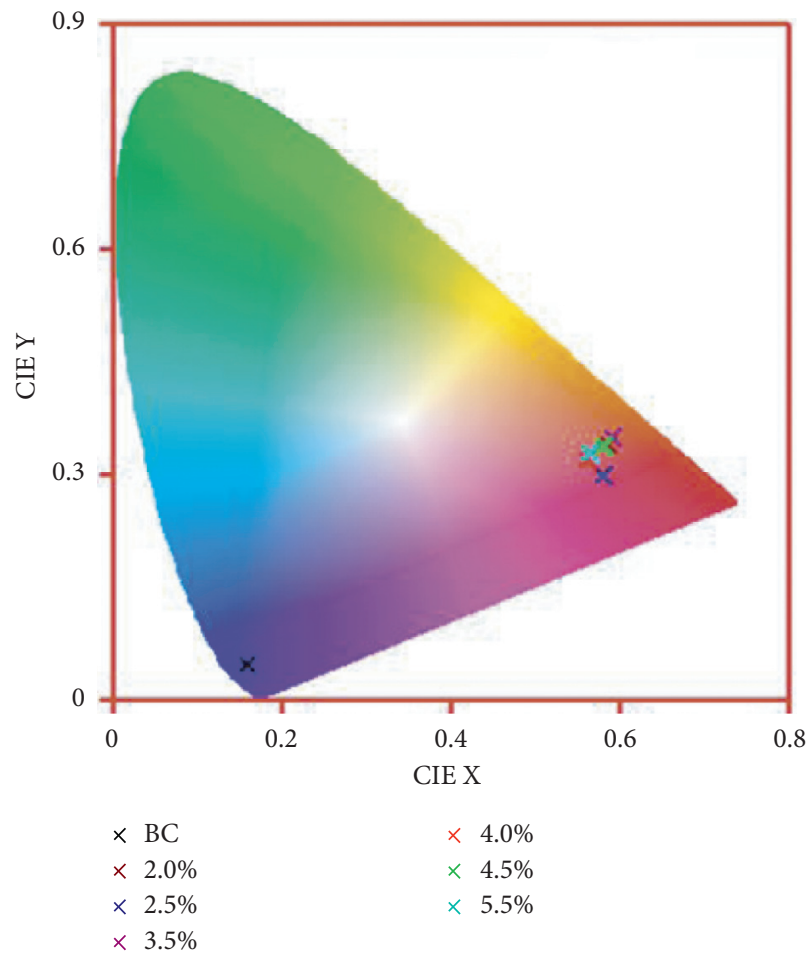

FIgURE 11: CIE chromaticity diagram for the BC and BC: $x \% \mathrm{Eu}^{3+}$ $(0 \leq x \leq 5.5)$ nanophosphors.

study. This explains why $294 \mathrm{~nm}$ was chosen as the preferred excitation wavelength in Figure 7(b).

Figures 9(a) and 9(b) and Table 3 show the decay curves of $\mathrm{Eu}^{3+}$ emission monitored at $436 \mathrm{~nm}$ for the undoped $\left(\mathrm{CaAl}_{4} \mathrm{O}_{7}\right.$, $\mathrm{BaAl}_{2} \mathrm{O}_{4}$, and $\left.\mathrm{BC}\right), \mathrm{BC}: x \% \mathrm{Eu}^{3+}(0 \leq x \leq 5.5)$ phases under $294 \mathrm{~nm}$ excitation and their kinetic analysis results, respectively. The lifetime decay curves shown in Figures 9(a) and 9(b) are well fitted with the first-order exponential decay equation:

$$
I(t)=A_{1} \exp \left(-\frac{t}{\tau_{1}}\right)
$$

where $I(t)$ is the luminescence intensity, $A_{1}$ is constant, $t$ is time, and $\tau_{1}$ is the luminescence lifetime for the exponential component, respectively. From these results, it can be seen that the samples have long-lasting afterglow decay. However, the decay lifetime of $\mathrm{BC}$ is shorter than those of $\mathrm{CaAl}_{4} \mathrm{O}_{7}$ and 
$\mathrm{BaAl}_{2} \mathrm{O}_{4}$. This may indicate that the electron trap levels in the mixed phase (BC) are shallower than those in $\mathrm{CaAl}_{2} \mathrm{O}_{4}$ and $\mathrm{BaAl}_{2} \mathrm{O}_{4}$. From Figure 9(b) and Table 3, it can be seen that the lifetime decay fluctuates as the concentration increases even though they follow the same trend. This suggests that the lifetime mostly depends on the defects within the mixed phase (BC). Figure 10 shows the logarithmic decay curves of $\mathrm{BC}: x \% \mathrm{Eu}^{3+}(0 \leq x \leq 5.5)$ samples. This was conducted to make the content of the plot more visible. It confirmed the discussion of Figure 9(b).

One of the main aims of this study was to investigate the application potential of $\mathrm{BC}: x \% \mathrm{Eu}^{3+}(0 \leq x \leq 5.5)$ nanophosphors. Therefore, the CIE coordinates shown in Table 3 were determined based on the emission spectra of the prepared nanophosphors. Figure 11 shows the CIE chromaticity diagram of the nanophosphors under the $294 \mathrm{~nm}$ excitation. From Figure 11, it appears that the colours of the doped samples are located in the orange-red region, while that of $\mathrm{BC}$ is in the blue region. This means that the doping was able to tune the colour from blue to orange-red. Therefore, the nanophosphor can be used to produce orange-red-emitting LEDs.

\section{Conclusion}

BC: $x \% \mathrm{Eu}^{3+}$ nanophosphors were successfully synthesized via sol-gel method. The results obtained from this study showed that the concentration of the dopant influences the morphology and the photoluminescence properties of the nanophosphors and not the microstructure. Furthermore, the PL intensity of $\mathrm{BC}$ is much higher than those of the pure $\mathrm{BaAl}_{2} \mathrm{O}_{4}$ and the pure $\mathrm{CaAl}_{4} \mathrm{O}_{7}$ phases. XRD, SEM, and TEM revealed that the microstructure consisted of hexagonal and monoclinic nanorods. The PL exhibits a weak peak at $436 \mathrm{~nm}$ due to the defects in $\mathrm{BC}$ matrix and one intense emission peak at 615 with a shoulder at $591 \mathrm{~nm}$ ascribed to the ${ }^{5} \mathrm{D}_{0} \longrightarrow{ }^{7} \mathrm{~F}_{2}$ and ${ }^{5} \mathrm{D}_{0} \longrightarrow{ }^{7} \mathrm{~F}_{1}$ transitions of $\mathrm{Eu}^{3+}$, respectively. This suggests that the electronic dipole transition is dominant. There is no reduction of $\mathrm{Eu}^{3+}$ to $\mathrm{Eu}^{2+}$. The longlasting afterglow is observed. CIE showed that the dopant was able to tune the emission colour from blue to orangered. These results demonstrate the promising application of the BC: $x \% \mathrm{Eu}^{3+}$ nanophosphors for the Near Ultraviolet(NUV-) based orange to red LEDs.

\section{Data Availability}

The data are available upon request.

\section{Conflicts of Interest}

The authors declare that they have no conflicts of interest.

\section{Acknowledgments}

This work was supported by the South African National Research Foundation (NRF) Thuthuka Programme (no. UID 99296) and Sefako Makgatho Health Sciences University.

\section{References}

[1] E. Nakazawa, Book of Phosphorspp. 3-6, Taylor \& Francis Group, LLC, Milton Park, Oxfordshire, UK, 2nd edition, 2006.

[2] P. Du, L. Krishna Bharat, and J. S. Yu, "Strong red emission in Eu3+/Bi3+ ions codoped CaWO4 phosphors for white lightemitting diode and field-emission display applications," Journal of Alloys and Compounds, vol. 633, pp. 37-41, 2015.

[3] K.-Y. Yeh and W.-R. Liu, "Luminescence properties of $\mathrm{NaCaGaSi} 2 \mathrm{O} 7$ :RE, $\mathrm{Li}+(\mathrm{RE}=\mathrm{Ce} 3+$, Eu 3+ or Tb 3+ ) phosphors for UV excitable white light emitting diodes," Materials Research Bulletin, vol. 80, pp. 127-134, 2016.

[4] R. Stefani, L. C. V. Rodrigues, C. A. A. Carvalho et al., "Persistent luminescence of Eu2+ and Dy3+ doped barium aluminate (BaAl2O4:Eu2+,Dy3+) materials," Optical Materials, vol. 31, no. 12, pp. 1815-1818, 2009.

[5] Z. Mu, Y. Hu, L. Chen, and X. Wang, "Enhanced red emission in ZnB2O4:Eu3+ by charge compensation," Opt. Matter, vol. 34, no. 24, pp. 89-94, 2011.

[6] T. Matsuzama, Y. Aoki, N. Takeuchi, and Y. Murayama, "Photoluminescence Behavior of BaAl12 O 19: Mn Phosphor Prepared by Pseudocombinatorial Chemistry Method," Journal of the Electrochemical Society, no. 11, p. 4368, 2000.

[7] D. Jia, X.-j. Wang, E. van der Kolk, and W. M. Yen, "Site dependent thermoluminescence of long persistent phosphorescence of $\mathrm{BaAl} 2 \mathrm{O} 4: \mathrm{Ce} 3+$, , Optics Communications, vol. 204, no. 1-6, pp. 247-251, 2002.

[8] D. Haranath, S. Pooja, C. Harish, A. Anwar, B. Nitesh, and S. K. Halder, "Fürs 1," Nachrichten aus der Chemie, vol. 58, no. 2, pp. 163-164, 2010.

[9] N. Avci, K. Korthout, M. A. Newton, P. F. Smet, and D. Poelman, "Valence states of europium in CaAl2O4:Eu phosphors," Optical Materials Express, vol. 2, pp. 321-330, 2012.

[10] A. N. Yerpude and S. J. Dhoble, "Combustion synthesis of blue-emitting submicronCaAl4O7:Eu2+,Dy3+persistence phosphor," Luminescence, vol. 27, pp. 450-454, 2012.

[11] B. Zhang, C. Zhao, and D. Chen, "Persistent luminescence mechanisms: human imagination at work," Luminescence, vol. 2, no. 25, pp. 25-29, 2010.

[12] B. Marí, K. C. Singh, N. Verma, M. Mollar, and J. Jindal, "Luminescence properties of Eu2+/Eu3+Activated barium aluminate phosphors with Gd3+Concentration variation," Transactions - Indian Ceramic Society, vol. 74, no. 3, pp. 157-161, 2015.

[13] F. M. Emen, N. Külcü, and A. N. Yazıc1, "Synthesis, characterization and luminescence properties of long afterglow Phosphor Ba4Al14O25:Eu,Dy," European Journal of Chemistry, vol. 1, no. 1, pp. 28-32, 2010.

[14] T. Aitasalo, J. Hölsä, H. Jungner et al., "Eu2+ doped calcium aluminates prepared by alternative low temperature routes," Optical Materials, vol. 26, no. 2, pp. 113-116, 2004.

[15] T. Aitasalo, J. Holsa, H. Jungner, M. Lastusaari, and J. Niittykoski, "Comparison of sol-gel and solid-state prepared Eu2+ doped calcium aluminates," Materials Science, vol. 20, pp. 15-20, 2002.

[16] N. Suriyamurthy and B. S. Panigrahi, "Luminescence of BaAl2O4:Mn2+,Ce3+ phosphor," Journal of Luminescence, vol. 127, no. 2, pp. 483-488, 2007.

[17] J.-M. Nedelec, "Sol-Gel Processing of Nanostructured Inorganic Scintillating Materials," Journal of Nanomaterials, vol. 2007, Article ID 36392, 8 pages, 2007. 
[18] J. Zhong, D. Chen, Y. Peng et al., "A review on nanostructured glass ceramics for promising application in optical thermometry," Journal of Alloys and Compounds, vol. 763, no. 763, pp. 34-48, 2018.

[19] X. Wang, Y. Wang, J. Yu, Y. Bu, and X. Yan, "Modifying phase, shape and optical thermometry of NaGdF 4:2\%Er 3+ phosphors through Ca 2+ doping," Optics Express, vol. 26, Article ID 21950, 2018.

[20] V. M. Maphiri, J. Wesley-Smith, and S. V. Motloung, "Phase transition and optical properties of Ba1-xZnxAl2O4:0.1\% Eu3+ prepared via citrate sol-gel method," Journal of Luminescence, vol. 215, no. 215, Article ID 116710, 2019.

[21] Y. Lv, K. Liu, J.-W. Shi et al., "Synthesis and luminescence studies of mixed phase LiCa3MgV3-XWXO12 phosphors for enhanced quantum yield," Journal of Luminescence, vol. 234, no. 234, Article ID 117948, 2021.

[22] A. N. Yerpude, S. J. Dhoble, and D. Haranath, "Synthesis and characterization of blue long-lasting BaCa2Al8O15:Eu2+, Dy3+phosphor," Luminescence, vol. 28, no. 4, pp. 437-441, 2013.

[23] A. N. Yerpude and S. J. Dhoble, "Luminescent properties of $\mathrm{Eu} 2+$ and $\mathrm{Dy} 3+$ ions in $\mathrm{Ba} 4 \mathrm{Al} 2 \mathrm{O} 7$ phosphor for solid state lighting," Journal of Luminescence, vol. 132, pp. 1781-1785, 2012.

[24] Chemiday.com, "The thermal decomposition of aluminum nitrate," 2021, https://chemiday.com/en/reaction/3-1-0-2644.

[25] S. Budavari, The Merck Index-Whitehouse, p. 275, Merck and Co., Inc., Station, NJ, USA, 1996.

[26] M. J. O'Neil, The Merck Index-Whitehouse, p. 165, Merck and Co., Inc., Station, NJ, USA, 2006.

[27] A. Altay, C. B. Carter, I. Arslan, and M. A. Gülgün, "Crystallization of CaAl4O7and CaAl12O19powders," Philosophical Magazine, vol. 89, no. 7, pp. 605-621, 2009.

[28] M. Pal, U. Pal, J. Miguel, G. Y. Jiménez, and F. PérezRodriguez, "Effects of crystallization and dopant concentration on the emission behavior of TiO2:Eu nanophosphors," Nanoscal. Res. Let.vol. 7, p. 1, 2012, http://www. nanoscalereslett.com/content/7/1/1.

[29] Z. Wang, S. Lou, and P. Li, "Single phase tunable warm whitelight-emitting Sr3La(PO4)3:Eu2+, Sm3+ phosphor for white LEDs," Optical Materials Express, vol. 6, pp. 114-125, 2015.

[30] V. A. Lubarda, "On the effective lattice parameter of binary alloys," Mechanics of Materials, vol. 35, no. 1-2, pp. 53-68, 2003.

[31] H. W. King, "Quantitative size-factors for metallic solid solutions," Journal of Materials Science, vol. 1, no. 1, pp. 79-90, 1966.

[32] S. V. Motloung, M. Tsega, F. B. Dejene et al., "Effect of annealing temperature on structural and optical properties of $\mathrm{ZnAl} 2 \mathrm{O} 4: 1.5 \% \mathrm{~Pb} 2+$ nanocrystals synthesized via sol-gel reaction," Journal of Alloys and Compounds, vol. 677, pp. 72-79, 2016.

[33] S. V. Motloung, F. B. Dejene, H. C. Swart, and O. M. Ntwaeaborwa, "Effects of $\mathrm{Pb} 2+$ ions concentration on the structure and $\mathrm{PL}$ intensity of $\mathrm{Pb}$-doped $\mathrm{ZnAl} 2 \mathrm{O} 4$ nanocrystals synthesized using sol-gel process," Journal of Sol-Gel Science and Technology, vol. 70, no. 3, pp. 422-427, 2014.

[34] M. R. Mhlongo, L. F. Koao, R. E. Kroon, and S. V. Motloung, "Analysis of $\mathrm{Nd} 3+$ concentration on the structure, morphology and photoluminescence of sol-gel Sr3ZnAl2O7 nanophosphor," Journal of Physiology \& Biochemistry, vol. 12, Article ID 411746, 2019.

[35] B. D. Cullity and S. R. Stock, Elements of X-ray Diffraction, Prentice Hall Publishers, Hoboken, NJ, USA, 3rd edition, 2001.
[36] V. D. Mote, Y. Purushotham, and B. M. Dole, "WilliamsonHall analysis in estimation of lattice strain in nanometer-sized ZnO particles," J. Theor. Appl. Phy.vol. 6, pp. 1-6, 2012.

[37] H. Bei, S. Shim, G. M. Pharr, and E. P. George, "Effects of prestrain on the compressive stress-strain response of Mo-alloy single-crystal micropillars," Acta Materialia, vol. 56, no. 17, pp. 4762-4770, 2008.

[38] Z. Pei, Q. Zheng, and Q. Su, "The application and substitution defect model for Eu3+ to Eu2+ reduction in non-reducing atmospheres in borates containing BO4 anion groups," Journal of Physics and Chemistry of Solids, vol. 6, pp. 9-12, 2000.

[39] M. Ziyauddin, N. Brahme, D. P. Bisen, and R. S. Kher, "Optical properties of calcium aluminate phosphors," Inter. Res. J. Eng. and Tech.no. 2, pp. 871-876, 2015.

[40] R. D. Shannon, "Revised effective ionic radii and systematic studies of interatomic distances in halides and chalcogenides," Acta Crystallographica A, vol. 32, pp. 751-767, 1976.

[41] Z. Zhang, A. C. A. Delsing, P. H. L. Notten, J. Zhao, P. Dorenbos, and H. T. Hintzen, "Photoluminescence properties of red-emitting $\mathrm{Mn}^{2+}$-activated CaAlSiN3Phosphor for white-LEDs," ECS Journal of Solid State Science and Technology, vol. 2, no. 4, pp. R70-R75, 2013.

[42] Q. Fei, C. Chang, and D. Mao, "Luminescent properties of $\mathrm{Sr}_{2} \mathrm{MgSi}_{2} \mathrm{O}_{7}$ and $\mathrm{Ca}_{2} \mathrm{MgSi}_{2} \mathrm{O}_{7}$ long lasting phosphors activated by $\mathrm{Eu}^{2+}, \mathrm{Dy}^{3+}, "$ Journal of Alloys and Compounds, vol. 390, no. 1-2, pp. 133-137, 2005. 